\title{
Evaluation of the combined expression of chemokine SDF-1 $\alpha$ and its receptor CXCR4 as a prognostic marker for gastric cancer
}

\author{
HYO JIN LEE ${ }^{1}$, SONG MEI HUANG ${ }^{2}$, HA YON KIM ${ }^{1}$, YOON SUK OH $^{1}$, \\ JI YOUNG HWANG ${ }^{1}$, ZHE LONG LIANG ${ }^{2}$, JEONG KI MIN ${ }^{4}$, HWAN JUNG YUN ${ }^{1}$, \\ JI YOUNG SUL ${ }^{3}$, SAMYONG KIM ${ }^{1}$, DEOG YEON JO ${ }^{1}$ and JIN MAN KIM ${ }^{2,5}$ \\ Departments of ${ }^{1}$ Internal Medicine, ${ }^{2}$ Pathology and ${ }^{3}$ Surgery, Cancer Research Institute, \\ Chungnam National University Hospital; ${ }^{4}$ Therapeutic Antibody Research Center, Korea Research Institute \\ of Bioscience and Biotechnology; ${ }^{5}$ Daejeon Regional Cancer Center and Infection Signaling Network \\ Research Center, Chungnam National University School of Medicine, Daejeon, Republic of Korea
}

Received January 14, 2011; Accepted March 14, 2011

DOI: $10.3892 / \mathrm{etm} .2011 .228$

\begin{abstract}
Chemokine stromal cell-derived factor (SDF)- $1 \alpha$ and its receptor CXC chemokine receptor 4 (CXCR4) have been shown to impact cancer progression. Accumulating evidence suggests that CXCR4 and SDF-1 $\alpha$ expression is useful for evaluating the risk of gastric cancer progression. Thus, combined analysis of SDF-1 $\alpha$ and CXCR4 should have high prognostic potential as a molecular marker for gastric cancer. We investigated the expression of SDF- $1 \alpha$ and CXCR4 using immunohistochemistry in relation to prognosis, clinicopathological features and clinical outcomes in 221 cases of primary gastric cancer. Patients were categorized into three groups according to CXCR4 and SDF-1 $\alpha$ expression: high CXCR4/ high SDF-1 $\alpha$, low CXCR4/low SDF-1 $\alpha$, and high CXCR4/low SDF-1 $\alpha$ - low CXCR4/high SDF-1 $\alpha$. No significant differences were noted in age, gender, histology, tumor location, lymphovascular invasion or proportion of tumor size $>5 \mathrm{~cm}$ among the three groups. However, high CXCR4/high SDF-1 $\alpha$ expression in tumor cells was significantly associated with depth of invasion of the tumor, lymph node involvement, and higher tumor stage compared to tumors with low CXCR4/low SDF-1 $\alpha$ expression or high CXCR4/low SDF-1 $\alpha$ - low CXCR4/high SDF-1 $\alpha$ expression. Furthermore, patients with high CXCR4/ high SDF-1 $\alpha$ expression had the worst patient prognosis, whereas patients who had low CXCR4/low SDF-1 $\alpha$ expression showed the most favorable prognosis. In conclusion, CXCR4 and SDF-1 $\alpha$ are useful prognostic factors in gastric cancer, and
\end{abstract}

Correspondence to: Professor Jin Man Kim, Department of Pathology and Infection Signaling Network Research Center, Chungnam National University School of Medicine, Daejeon, Republic of Korea

E-mail: jinmank@cnu.ac.kr

Key words: stromal cell-derived factor- $1 \alpha$, CXC chemokine receptor 4, gastric cancer, prognosis the combination of high CXCR4 protein expression with high SDF-1 $\alpha$ expression suggests a dismal prognosis.

\section{Introduction}

Gastric cancer is a major public health problem. It is the fourth most common cancer worldwide, with 603,000 new cases among men and 330,000 among women annually. Gastric cancer is the second leading cause of cancer-related mortality, with 700,000 deaths per year worldwide $(1,2)$. Although surgical resection remains the primary treatment option, a substantial proportion of patients with gastric cancer who have undergone curative surgery develops disease recurrence. Overall survival outcomes remain unsatisfactory, although histopathological features such as depth of invasion of the primary tumor and lymph node involvement used as prognostic factors have improved survival rates. Numerous studies have attempted to determine the optimal method to estimate gastric cancer prognosis using molecular markers $(3,4)$.

Chemokines and their receptors, particularly stromal cell-derived factor (SDF)- $1 \alpha$ and CXC chemokine receptor 4 (CXCR4), have been shown to impact cancer progression. CXCR4 is a key receptor in the crosstalk between tumor cells and their microenvironment. Mesenchymal or marrowderived stromal cells, which constitute a large proportion of the non-neoplastic cells within the tumor microenvironment, secrete SDF-1 $\alpha(5,6)$. SDF- $1 \alpha$ is also produced by various types of tumor cells and may act in an autocrine and paracrine manner (7-9). The pattern of CXCR4 expression in tumor cells has a critical role in determining the site of metastatic spread, as cancer cells that express CXCR4 are attracted to organs in which SDF-1 $\alpha$ is secreted (10). SDF-1 $\alpha$ induces proliferation, invasion and survival of cancer cells, and promotes tumor angiogenesis (11-13). Thus, CXCR4 and SDF-1 $\alpha$ expression is associated with disease progression and consequently could serve as a prognostic marker in various cancer types (14-16). 
Accumulating evidence suggests that CXCR4 and SDF-1 $\alpha$ expression is useful for evaluating the risk of gastric cancer progression. CXCR4 expression is associated with lymph node metastasis and development of peritoneal carcinomatosis in patients with gastric cancer (17-21), and SDF-1 $\alpha$ expression in the primary cancer is reported to be an independent prognostic factor in these patients (22). Thus, combined analysis of SDF-1 $\alpha$ and CXCR4 would have strong prognostic potential as a molecular marker for gastric cancer.

The aim of our study was to investigate the relationship between combined SDF-1 $\alpha$ and CXCR4 expression and prognosis and survival rates in human gastric cancer. Immunohistochemistry was used to examine SDF-1 $1 \alpha$ expression in tissue from 221 patients with gastric cancer in which we previously assessed CXCR4 expression (21). We also analyzed the relationship between combined CXCR4 and SDF-1 $\alpha$ expression and gastric cancer prognosis.

\section{Materials and methods}

Patients and tumor samples. This study used tissue samples from 221 patients undergoing elective surgery for gastric cancer at Chungnam National University Hospital, Daejeon, Korea, between 2000 and 2003. All patients had participated in our previous study which investigated the impact of CXCR4 expression on gastric cancer progression (21). Data from this previous study are discussed here for the purpose of combined analysis of SDF- $1 \alpha$ and CXCR4 expression. The patient population included 155 men and 66 women, ranging in age from 29 to 86 years (mean, 58.6). Patients had histologically confirmed adenocarcinoma; clinicopathological features were assessed using the general guidelines established by the Japanese Gastric Cancer Association (23). No patients had received preoperative chemotherapy. All protocols were approved by the institutional review board.

Immunohistochemical staining of SDF-1 $\alpha$. Immunohistochemical staining was performed using monoclonal anti-SDF-1 $\alpha$ antibodies (MAB350; R\&D Systems, Minneapolis, MN) and the Envision-HRP detection system (DakoCytomation, Carpinteria, CA) according to the manufacturers' protocols. Sections $(3 \mu \mathrm{m})$ were cut from gastric cancer tissue microarray blocks, mounted on slides treated with APES (Sigma Chemical Co., St. Louis, MO), and dried for $2 \mathrm{~h}$ at $56^{\circ} \mathrm{C}$ before staining. Briefly, the sections were deparaffinized in xylene and rehydrated in graded alcohol. After antigen retrieval by heating with citrate buffer ( $\mathrm{pH}$ 6.0) in a pressure cooker at full power for $3 \mathrm{~min}$, tissue sections were treated with $3 \%$ hydrogen peroxide for $10 \mathrm{~min}$ to block endogenous peroxidases. The sections were then incubated for $30 \mathrm{~min}$ in a humid chamber at room temperature with the anti-SDF-1 $\alpha$ antibody (1:50) diluted with background reducing diluent (S0809; DakoCytomation). Slides were then incubated with Envision reagent for $30 \mathrm{~min}$, followed by 3,3'-diamino-benzidine (DAB) chromogen for $5 \mathrm{~min}$, counterstained with Mayer's hematoxylin and mounted. Exclusion of the primary antibody during immunostaining was used as a negative control, while lymphocytes of normal spleen sections served as a positive control. Immunostaining was evaluated independently by two authors (S.M.H., J.M.K.) who were blinded to the patient outcomes and clinicopathological findings. Immunohistochemical staining was scored according to intensity, and tumors were classified according to four grades based on staining intensity (grade 0 , no staining intensity; grade 1, weak staining intensity; grade 2, moderate staining intensity; grade 3 , strong staining intensity). In the case of heterogeneous sample staining, the higher score was chosen when more than $50 \%$ of the cells showed greater staining intensity. Relative expression of SDF-1 $\alpha$ was indicated by its staining intensity (i.e., strong staining indicated high SDF-1 $\alpha$ expression and vice versa), as in our previous report in which we used the same defining system for CXCR4 (21).

Statistical analysis. The association of SDF- $1 \alpha$ and CXCR4 expression with clinicopathologic features was assessed using the $\chi^{2}$ test and Student's t-test. Survival rates were determined using Kaplan-Meier curves, and P-values were determined by the log-rank test, with $\mathrm{P}<0.05$ considered to be statistically significant. All statistical analyses were conducted using SPSS 13.0 (SPSS, Chicago, IL).

\section{Results}

Correlation between SDF-1 $\alpha$ expression and clinicopathological factors. SDF-1 $\alpha$ was detected in the cytoplasm and cellular membrane of the gastric cancer cells. The stromal cells lacked staining for SDF-1 $\alpha$. SDF-1 $\alpha$ expression was variable (no staining, $52.5 \%$ of samples; weak staining, $19.9 \%$; moderate staining, $14.9 \%$; strong staining, $12.7 \%$ ) (Fig. 1). No significant differences existed in age, gender, histology, tumor location, lymphatic invasion, venous invasion, or proportion of tumor size $>5 \mathrm{~cm}$ between the high SDF-1 $\alpha$ expression and low SDF-1 $\alpha$ expression groups. However, the high SDF-1 $\alpha$ expression group was found to have a tendency to have more lymph node involvement. Furthermore, high SDF-1 $\alpha$ expression was significantly correlated with depth of invasion of the tumor $(\mathrm{P}<0.001)$ and a more advanced tumor stage $(\mathrm{P}=0.006)$ (Table I). Patients with high SDF-1 $\alpha$ expression exhibited a significantly reduced 5-year survival rate compared to patients with low SDF-1 $\alpha$ expression (35.7 vs. 50.8\%; $\mathrm{P}=0.045$, logrank test) as depicted in the survival curve in Fig. 2A.

Correlation between the combination of CXCR4/SDF-1 $\alpha$ expression and clinicopathological factors. Table II shows the clinicopathological features associated with CXCR4 and SDF-1 $\alpha$ expression in patients with gastric cancer. Patients were categorized into three groups according to CXCR4 and SDF-1 $\alpha$ expression: high CXCR4/high SDF-1 $\alpha$, low CXCR4/ low SDF-1 $\alpha$, and high CXCR4/low SDF-1 $\alpha$ - low CXCR4/high SDF-1 $\alpha$. High CXCR4/high SDF-1 $\alpha$ tumors were significantly correlated with depth of tumor invasion $(\mathrm{P}=0.001)$, lymph node involvement $(\mathrm{P}=0.029)$, and a more advanced stage $(\mathrm{P}=0.001)$ (Table II). Fig. 2B shows the survival curves of patients according to CXCR4 and SDF- $1 \alpha$ expression. Patients with high CXCR4/high SDF-1 $\alpha$ tumors had the least favorable prognosis (5-year survival rate, 26.7\%; median, 2.2 years), whereas patients with low CXCR4/low SDF-1 $\alpha$ expression showed the most favorable prognosis (5-year survival rate, 57\%; median, not reached; log-rank test, $\mathrm{P}=0.01$ ) (Fig. 2B). 

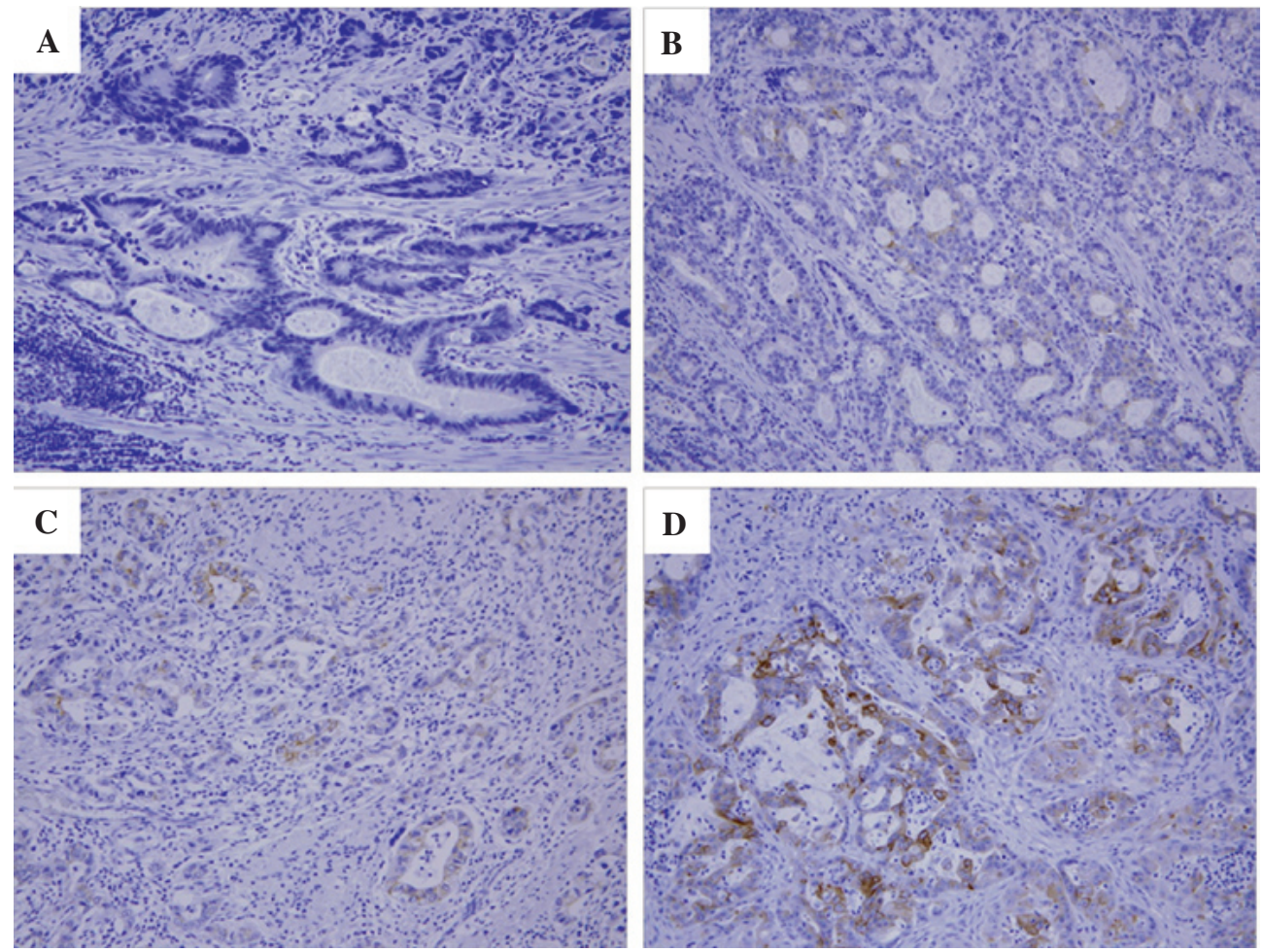

Figure 1. Representative photomicrographs of SDF-1 $\alpha$ immunohistochemical staining in human gastric cancer tissues. (A) No staining intensity. (B) Weak staining intensity. (C) Moderate staining intensity. (D) Strong staining intensity. (x200).

A

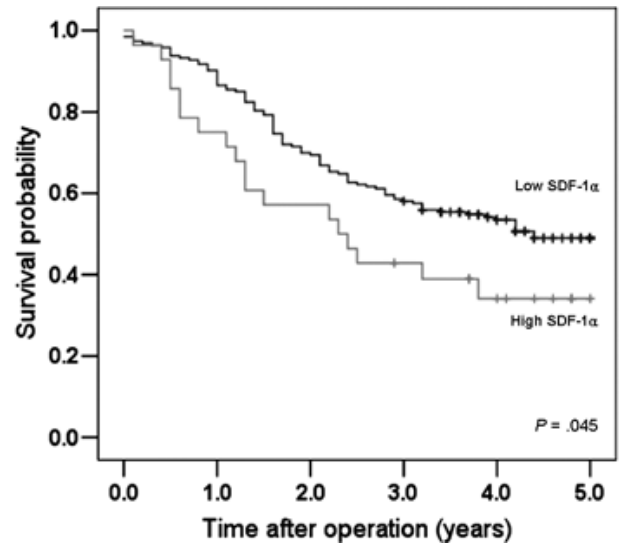

B

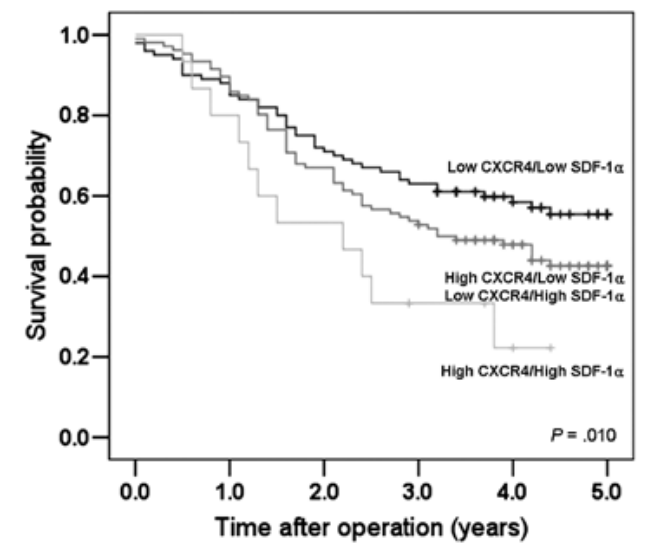

Figure 2. Survival curves for the gastric cancer patients according to CXCR4 and SDF-1 $\alpha$ expression. (A) Patients with high SDF-1 $\alpha$ expression had shorter survival times than those with low SDF-1 $\alpha$ expression. (B) A significant difference was observed among groups stratified according to CXCR4 and SDF-1 $\alpha$ expression. Patients with high CXCR4 and high SDF-1 $\alpha$ expression had the worst prognosis.

\section{Discussion}

The chemokine receptor CXCR4 and its ligand SDF-1a promote tumor progression by a variety of direct and indirect mechanisms. First, CXCR4 is essential for metastatic spread to organs in which SDF-1 $\alpha$ is expressed, thereby allowing tumor cells to access cellular niches that favor tumor cell survival and growth (6). For example, Müller et al reported that high CXCR4 expression is found in human breast cancer cell lines and primary breast tumors and that lymph nodes, representative metastatic sites of breast cancer, highly express SDF-1 $\alpha$ (10). Second, SDF-1 $\alpha$ can itself stimulate the survival and growth of tumor cells via autocrine and paracrine actions
(6). Orimo et al reported that SDF-1 $\alpha$ significantly affects CXCR4-expressing human breast carcinomas through direct paracrine stimulation (13). Barbieri et al (8) and Kim et al (24) also reported that SDF-1 $\alpha$ promotes human pituitary tumor cell and myeloma cell proliferation, respectively. In addition, SDF-1 $\alpha$ can promote tumor angiogenesis by attracting endothelial cells to the tumor microenvironment. Inhibition of the CXCR4/SDF-1 $\alpha$ pathway decreases the growth of gastrointestinal tumors through suppression of angiogenesis $(13,25)$. Thus, CXCR4 and SDF-1 $\alpha$ expression may represent a valuable prognostic marker for various types of cancer. Furthermore, preclinical tumor models indicate that CXCR4 antagonists may have antitumor activity, suggesting that 
Table I. Clinicopathological features of the gastric cancer patients according to SDF- $1 \alpha$ expression.

\begin{tabular}{|c|c|c|c|}
\hline & \multicolumn{2}{|c|}{ SDF- $1 \alpha$ expression } & \multirow[b]{2}{*}{ P-value } \\
\hline & $\begin{array}{c}\text { Low }(\mathrm{n}=193) \\
\text { No. }(\%)\end{array}$ & $\begin{array}{c}\text { High }(\mathrm{n}=28) \\
\text { No. }(\%)\end{array}$ & \\
\hline Age, mean \pm SEM (years) & $58.3 \pm 11.2$ & $60.9 \pm 11.2$ & 0.256 \\
\hline $\begin{array}{l}\text { Gender } \\
\text { Male } \\
\text { Female }\end{array}$ & $\begin{array}{r}133(68.9) \\
60(31.1)\end{array}$ & $\begin{array}{r}22(78.6) \\
6(21.4)\end{array}$ & 0.411 \\
\hline $\begin{array}{l}\text { Depth of invasion } \\
\text { T1, T2 } \\
\text { T3, T4 }\end{array}$ & $\begin{array}{r}153(79.3) \\
40(20.7)\end{array}$ & $\begin{array}{l}13(46.4) \\
15(53.6)\end{array}$ & $<0.001$ \\
\hline $\begin{array}{l}\text { Nodal involvement } \\
\text { Negative } \\
\text { Positive }\end{array}$ & $\begin{array}{r}120(62.2) \\
73(37.8)\end{array}$ & $\begin{array}{l}13(46.4) \\
15(53.6)\end{array}$ & 0.112 \\
\hline $\begin{array}{l}\text { Stage } \\
\text { I, II } \\
\text { III, IV }\end{array}$ & $\begin{array}{r}160(82.9) \\
33(17.1)\end{array}$ & $\begin{array}{l}17(60.7) \\
11(39.3)\end{array}$ & 0.006 \\
\hline $\begin{array}{l}\text { Histology } \\
\text { Differentiated } \\
\text { Undifferentiated }\end{array}$ & $\begin{array}{r}93(48.2) \\
100(51.8)\end{array}$ & $\begin{array}{l}12(42.9) \\
16(57.1)\end{array}$ & 0.598 \\
\hline $\begin{array}{l}\text { Tumor location } \\
\text { Upper } \\
\text { Middle } \\
\text { Lower } \\
\text { Whole }\end{array}$ & $\begin{array}{r}11(5.7) \\
101(52.3) \\
79(40.9) \\
2(1.0)\end{array}$ & $\begin{array}{r}1 \\
16(3.6) \\
11(39.1) \\
0 \quad(0.0)\end{array}$ & 0.892 \\
\hline $\begin{array}{l}\text { Lymphatic invasion } \\
\text { Negative } \\
\text { Positive }\end{array}$ & $\begin{array}{r}147(76.2) \\
46(23.8)\end{array}$ & $\begin{array}{r}23(82.1) \\
5(17.9)\end{array}$ & 0.483 \\
\hline $\begin{array}{l}\text { Venous invasion } \\
\text { Negative } \\
\text { Positive }\end{array}$ & $\begin{array}{r}145(75.1) \\
48(24.9)\end{array}$ & $\begin{array}{r}24(85.7) \\
4(14.3)\end{array}$ & 0.217 \\
\hline $\begin{array}{l}\text { Tumor size }(\mathrm{cm}) \\
\leq 5 \\
>5\end{array}$ & $\begin{array}{r}158(81.9) \\
35(18.1)\end{array}$ & $\begin{array}{r}19(67.9) \\
9(32.1)\end{array}$ & 0.138 \\
\hline
\end{tabular}

CXCR4 and SDF-1 $\alpha$ play important roles in the spread and progression of a variety of different tumors, and thus may also be potential targets for novel therapies $(6,26)$.

We previously reported that high CXCR4 expression in gastric cancer was associated with lymph node metastasis and higher tumor stage, and was also correlated with reduced 5 -year survival rates (21). Arigami et al (17) and Iwasa et al (27) also demonstrated that CXCR4 expression was significantly correlated with lymph node metastasis and/or liver metastasis. Additionally, Yasumoto et al (18) and Zieker et al (20) reported that CXCR4 and/or SDF-1 $\alpha$ expression in gastric cancer was correlated with the development of peritoneal carcinomatosis both in vivo and in vitro, whereas Tsuboi et al demonstrated that CXCR4/SDF-1 $\alpha$ expression is more strongly associated with lymphatic or hematogenous metastasis than with the development of peritoneal deposits (28).
Furthermore, Ishigami et al reported that SDF-1 $\alpha$ expression was an independent prognostic factor for aggressive behavior in gastric cancer (22). In this study, high SDF-1 $\alpha$ expression in tumor cells was significantly correlated with depth of invasion of the tumor and tumor stage, and also was associated with a greater degree of lymph node involvement. Moreover, patients with high SDF-1 $\alpha$ expression showed significantly reduced 5 -year survival rates. Taken together, these results confirm that CXCR4 and SDF-1 $\alpha$ expression represents a prognostic marker in human gastric cancer, suggesting that a combined analysis of CXCR4 and SDF-1 $\alpha$ would be even more informative in predicting prognosis. However, no data exist concerning the combined analysis of CXCR4 and SDF- $1 \alpha$ expression in relation to gastric cancer prognosis.

In the present study, we investigated for the first time the effects of the combination of CXCR4 and SDF- $1 \alpha$ expres- 
Table II. Clinicopathological features of the gastric cancer patients according to CXCR4/SDF-1 $\alpha$ expression.

\begin{tabular}{|c|c|c|c|c|}
\hline & $\begin{array}{l}\text { Low CXCR4/ } \\
\text { low SDF-1 } \alpha \\
(\mathrm{n}=100) \\
\text { No. }(\%)\end{array}$ & $\begin{array}{l}\text { High CXCR4/low SDF-1 } \alpha \\
\text { Low CXCR4/high SDF-1 } \alpha \\
\qquad \begin{array}{c}(\mathrm{n}=106) \\
\text { No. }(\%)\end{array}\end{array}$ & $\begin{array}{l}\text { High CXCR4/ } \\
\text { high SDF-1 } \\
(\mathrm{n}=15) \\
\text { No. }(\%)\end{array}$ & $\mathrm{P}$-value \\
\hline Age, mean \pm SEM (years) & $58.3 \pm 11.7$ & $58.5 \pm 10.7$ & $61.5 \pm 11.3$ & 0.578 \\
\hline Gender & & & & 0.525 \\
\hline Male & $67(67.0)$ & $76(71.7)$ & $12(80.0)$ & \\
\hline Female & $33(33.0)$ & $30(28.3)$ & $3(20.0)$ & \\
\hline Depth of invasion & & & & 0.001 \\
\hline $\mathrm{T} 1, \mathrm{~T} 2$ & $84(84.0)$ & $76(71.7)$ & $6(40.0)$ & \\
\hline $\mathrm{T} 3, \mathrm{~T} 4$ & $16(16.0)$ & $30(28.3)$ & $9(60.0)$ & \\
\hline Nodal involvement & & & & 0.029 \\
\hline Negative & $69(69.0)$ & $58(54.7)$ & $6(40.0)$ & \\
\hline Positive & $31(31.0)$ & $48(45.3)$ & $9(60.0)$ & \\
\hline Stage & & & & 0.001 \\
\hline I, II & $87(87.0)$ & $83(78.3)$ & $7(46.7)$ & \\
\hline III, IV & $13(13.0)$ & $23(21.7)$ & $8(53.3)$ & \\
\hline Histology & & & & 0.985 \\
\hline Differentiated & $47(47.0)$ & $51(48.1)$ & $7(46.7)$ & \\
\hline Undifferentiated & $53(53.0)$ & $55(51.9)$ & $8(53.3)$ & \\
\hline Tumor location & & & & 0.254 \\
\hline Upper & $3(3.0)$ & $9(8.5)$ & $0 \quad(0.0)$ & \\
\hline Middle & $56(56.0)$ & $51(48.1)$ & $10(66.7)$ & \\
\hline Lower & $39(39.0)$ & $46(43.4)$ & $5(33.3)$ & \\
\hline Whole & $2(2.0)$ & $\begin{array}{ll}0 & (0.0)\end{array}$ & $0 \quad(0.0)$ & \\
\hline Lymphatic invasion & & & & 0.362 \\
\hline Negative & $73(73.0)$ & $86(81.1)$ & $11(73.3)$ & \\
\hline Positive & $27(27.0)$ & $20(18.9)$ & $4(26.7)$ & \\
\hline Venous invasion & & & & 0.541 \\
\hline Negative & $73(73.0)$ & $84(79.2)$ & $12(80.0)$ & \\
\hline Positive & $27(27.0)$ & $22(20.8)$ & $3(20.0)$ & \\
\hline Tumor size $(\mathrm{cm})$ & & & & 0.157 \\
\hline$\leq 5$ & $85(85.0)$ & $82(77.4)$ & $10(66.7)$ & \\
\hline$>5$ & $15(15.0)$ & $24(22.6)$ & $5(33.3)$ & \\
\hline
\end{tabular}

sion on the prognosis of patients with gastric cancer. High CXCR4/high SDF-1 $\alpha$ expression was significantly correlated with tumor invasion, lymphatic metastasis and higher tumor stage. Furthermore, patients with high CXCR4/high SDF-1 $\alpha$ expression had the least favorable prognosis, whereas patients with low CXCR4/low SDF-1 $\alpha$ expression showed the most favorable prognosis. Thus, our results suggest that the expression of CXCR4 and SDF-1 $\alpha$ in human gastric cancer is a useful molecular marker for assessing the risk of disease progression.

The present study has some limitations. As the determination of CXCR4 and SDF-1 $\alpha$ expression was dependent solely on immunohistochemistry, the possibility exists of errors due to diagnostic inaccuracy. To obtain more accurate results, several other methods such as Western blotting, quantitative mRNA expression, or gene expression profiling should be considered simultaneously. Also, all clinicopathological data were collected retrospectively. Accordingly, a well-planned prospective study incorporating multiple validating techniques such as Western blotting is warranted in the future. In conclusion, CXCR4 and SDF-1 $\alpha$ expression may reflect the prognosis of patients with gastric cancer, such that a combination of high CXCR4 and high SDF-1 $\alpha$ expression suggests a dismal prognosis.

\section{Acknowledgements}

This study was supported, in part, by the Basic Science Research Program through the National Research Foundation of Korea (NRF) funded by the Ministry of Education, Science and Technology (NRF-2009-0076540, NRF-2009-0067256), Chungnam National University Hospital Research Fund, 
2009 and the National Research Foundation of Korea (NRF) grant funded by the Korea government (MEST) (No. 20100001284: 2010-0001287) and by a grant from the National R\&D Program for Cancer Control Ministry of Health and Welfare, Republic of Korea. (No: 0720560). .

\section{References}

1. Kamangar F, Dores GM and Anderson WF: Patterns of cancer incidence, mortality, and prevalence across five continents: defining priorities to reduce cancer disparities in different geographic regions of the world. J Clin Oncol 24: 2137-2150, 2006.

2. Parkin DM, Bray F, Ferlay $\mathrm{J}$ and Pisani P: Global cancer statistics. 2002. CA Cancer J Clin 55: 74-108, 2005.

3. Hermans J, Bonenkamp JJ, Boon MC, et al: Adjuvant therapy after curative resection for gastric cancer: meta-analysis of randomized trials. J Clin Oncol 11: 1441-1447, 1993.

4. Jackson CB and Giraud AS: STAT3 as a prognostic marker in human gastric cancer. J Gastroenterol Hepatol 24: 505-507, 2009.

5. Arya M, Patel HR and Williamson M: Chemokines: key players in cancer. Curr Med Res Opin 19: 557-564, 2003.

6. Burger JA and Kipps TJ: CXCR4: a key receptor in the crosstalk between tumor cells and their microenvironment. Blood 107: 1761-1767, 2006

7. Scotton CJ, Wilson JL, Scott K, et al: Multiple actions of the chemokine CXCL12 on epithelial tumor cells in human ovarian cancer. Cancer Res 62: 5930-5938, 2002.

8. Barbieri F, Bajetto A, Stumm R, et al: Overexpression of stromal cell-derived factor 1 and its receptor CXCR4 induces autocrine/ paracrine cell proliferation in human pituitary adenomas. Clin Cancer Res 14: 5022-5032, 2008.

9. Koshiba T, Hosotani R, Miyamoto Y, et al: Expression of stromal cell-derived factor 1 and CXCR4 ligand receptor system in pancreatic cancer: a possible role for tumor progression. Clin Cancer Res 6: 3530-3535, 2000.

10. Muller A, Homey B, Soto H, et al: Involvement of chemokine receptors in breast cancer metastasis. Nature 410: 50-56, 2001

11. Ganju RK, Brubaker SA, Meyer J, et al: The alpha-chemokine, stromal cell-derived factor-1, binds to the transmembrane G-protein-coupled CXCR-4 receptor and activates multiple signal transduction pathways. J Biol Chem 273: 23169-23175, 1998.

12. Oh JW, Drabik K, Kutsch O, Choi C, Tousson A and Benveniste EN: CXC chemokine receptor 4 expression and function in human astroglioma cells. J Immunol 166: 2695-2704, 2001.

13. Orimo A, Gupta PB, Sgroi DC, et al: Stromal fibroblasts present in invasive human breast carcinomas promote tumor growth and angiogenesis through elevated SDF-1/CXCL12 secretion. Cell 121: 335-348, 2005.
14. Mirisola V, Zuccarino A, Bachmeier BE, et al: CXCL12/SDF1 expression by breast cancers is an independent prognostic marker of disease-free and overall survival. Eur J Cancer 45: 2579-2587, 2009.

15. Yoshitake N, Fukui H, Yamagishi H, et al: Expression of SDF-1 alpha and nuclear CXCR4 predicts lymph node metastasis in colorectal cancer. Br J Cancer 98: 1682-1689, 2008.

16. Schimanski CC, Schwald S, Simiantonaki N, et al: Effect of chemokine receptors CXCR4 and CCR7 on the metastatic behavior of human colorectal cancer. Clin Cancer Res 11: 1743-1750, 2005.

17. Arigami T, Natsugoe S, Uenosono Y, et al: CCR7 and CXCR4 expression predicts lymph node status including micrometastasis in gastric cancer. Int J Oncol 35: 19-24, 2009.

18. Yasumoto K, Koizumi K, Kawashima A, et al: Role of the CXCL12/CXCR4 axis in peritoneal carcinomatosis of gastric cancer. Cancer Res 66: 2181-2187, 2006.

19. Hashimoto I, Koizumi K, Tatematsu M, et al: Blocking on the CXCR4/mTOR signalling pathway induces the anti-metastatic properties and autophagic cell death in peritoneal disseminated gastric cancer cells. Eur J Cancer 44: 1022-1029, 2008.

20. Zieker D, Königsrainer I, Traub F, et al: PGK1 a potential marker for peritoneal dissemination in gastric cancer. Cell Physiol Biochem 21: 429-436, 2008.

21. Lee HJ, Kim SW, Kim HY, et al: Chemokine receptor CXCR4 expression, function, and clinical implications in gastric cancer. Int J Oncol 34: 473-480, 2009.

22. Ishigami $\mathrm{S}$, Natsugoe $\mathrm{S}$, Okumura $\mathrm{H}$, et al: Clinical implication of CXCL12 expression in gastric cancer. Ann Surg Oncol 14: 3154-3158, 2007.

23. Japanese Gastric Cancer Association: Japanese Classification of Gastric Carcinoma. 2nd English edition. Gastric Cancer 1: 10-24, 1998.

24. Kim SW, Kim HY, Lee HJ, Yun HJ, Kim S and Jo DY: Stromal cell-derived factor-1 promotes myeloma cell growth in both aurocrine and paracrine manners. Korean J Hematol 43: 127-137, 2008.

25. Guleng B, Tateishi K, Ohta M, et al: Blockade of the stromal cellderived factor-1/CXCR4 axis attenuates in vivo tumor growth by inhibiting angiogenesis in a vascular endothelial growth factorindependent manner. Cancer Res 65: 5864-5871, 2005

26. Schimanski CC, Galle PR and Moehler M: Chemokine receptor CXCR4 - prognostic factor for gastrointestinal tumors. World J Gastroenterol 14: 4721-4724, 2008.

27. Iwasa S, Yanagawa T, Fan J and Katoh R: Expression of CXCR4 and its ligand SDF-1 in intestinal-type gastric cancer is associated with lymph node and liver metastasis. Anticancer Res 29: 4751-4758, 2009.

28. Tsuboi K, Kodera Y, Nakanishi H, et al: Expression of CXCL12 and CXCR4 in pT3-stage gastric cancer does not correlate with peritoneal metastasis. Oncol Rep 20: 1117-1123, 2008. 